\title{
Correction to: Towards policies that capture the expected value of biomolecular diversity for drug discovery, human health, and well-being
}

\author{
Milica Pesic ${ }^{1,2} \cdot$ Dilfuza Egamberdieva ${ }^{1,3} \cdot$ Bartlomiej Kolodziejczyk $^{1,4} \cdot$ Simon J. Elsässer $^{1,5}$ (D) \\ Vidushi S. Neergheen $^{1,6} \cdot$ Alexander Kagansky ${ }^{1,7}$
}

Published online: 23 September 2020

(c) The Author(s) 2020

\section{Correction to: Biologia Futura https://doi.org/10.1007/s42977-020-00043-3}

The third author's given name was incomplete in the initial online publication. The original article has been corrected.
Open Access This article is licensed under a Creative Commons Attribution 4.0 International License, which permits use, sharing, adaptation, distribution and reproduction in any medium or format, as long as you give appropriate credit to the original author(s) and the source, provide a link to the Creative Commons licence, and indicate if changes were made. The images or other third party material in this article are included in the article's Creative Commons licence, unless indicated otherwise in a credit line to the material. If material is not included in the article's Creative Commons licence and your intended use is not permitted by statutory regulation or exceeds the permitted use, you will need to obtain permission directly from the copyright holder. To view a copy of this licence, visit http://creativecommons.org/licenses/by/4.0/.
The original article can be found online at https://doi.org/10.1007/ s42977-020-00043-3.

\section{Simon J. Elsässer}

simon.elsasser@scilifelab.se

$\triangle$ Alexander Kagansky

kagasha@yahoo.com

Milica Pesic

camala@ibiss.bg.ac.rs

Dilfuza Egamberdieva

egamberdieva@yahoo.com

Bartlomiej Kolodziejczyk

kolodziejczykbartlomiej@gmail.com

Vidushi S. Neergheen

v.neergheen@uom.ac.mu

1 'Biodiversity for Survival via Biomedicine' Working Group, Global Young Academy, Halle (Saale), Germany

2 Institute for Biological Research "Siniša Stanković".

National Institute of Republic of Serbia, University

of Belgrade, Belgrade, Serbia
3 Faculty of Biology, National University of Uzbekistan, Tashkent, Uzbekistan

4 Department of Pedagogical, Curricular and Professional Studies, University of Gothenburg, Gothenburg, Sweden

5 Science for Life Laboratory, Division of Genome Biology, Department of Medical Biochemistry and Biophysics, Karolinska Institutet, Stockholm, Sweden

6 Department of Health Sciences, Faculty of Science and Centre for Biomedical and Biomaterials Research, University of Mauritius, Réduit, Republic of Mauritius

7 Centre for Genomic and Regenerative Medicine, School of Biomedicine, Far Eastern Federal University, Vladivostok, Russian Federation 